\title{
Image Processing and Arduino Interface Application for Automated Desk
}

\author{
Roucoz EI MORR ${ }^{1}$, Dr. Eylem GÜLCE ÇOKER ${ }^{2}$ \\ ${ }^{1}$ Department of Electrical and Electronics Engineering, Istanbul Aydin University, \\ Beşyol, İnönü Cd. No:38, 34295Küçükçekmece, Istanbul, Turkey \\ roucozmorr@stu.aydin.edu.tr \\ ${ }^{2}$ Department of Electrical and Electronics Engineering, Istanbul Aydin University \\ Beşyol, İnönü Cd. No:38, 34295Küçükçekmece, Istanbul, Turkey \\ eylemcoker@aydin.edu.tr
}

\begin{abstract}
This paper focuses on a large research program.The 21st century is the digital age where books are replaced by technological gadgets, and where employees, office workers, students, and managers spend a lot of hours sitting in the same position, focusing on small screens, writing reports, and achieving their own daily stuff without noticing that their health is negatively affected, hence suffering from health problems that limit their creativity and productivity. Smart Desk is an innovative solution that registers a person's daily routine, gently notifies him/her of the best times to sit and stand. It is a combination of a desk with sensors and an application that consists of a schedule program where all orders are received by the Arduino controller, via Bluetooth, which orders the motor driver to achieve the corresponding output.The system is designed with a dual mode: "Student Mode" and "Worker Mode" where the user specifies which mode to be displayed with its relative features. In both modes, there is a reminder system that allows the user to have a private desk that is customized to order food, call a taxi/partner, opens a music, control the light projection and the temperature with respect to the environment, force the worker to drink and do stretching activities after a sufficient time of sitting by adjusting the desk with respect to the height so it can move up or down, manually and automatically. Also, the desk is qualified by a voice recognition system to ensure security, and a camera based on image processing system to recognize any person and give information about him.
\end{abstract}

Keywords: smart desk, image processing, Arduino, windows application, mechanical design

\section{Introduction}

Following up the technological development requires sacrifice of many human needs specifically health needs. Working for long period of times finishing reports, doing research, designing new products... these entire tasks tires human's body. Almost every problem faced by office workers is related to physical disorders caused by sitting for too long gazing at their desktop's screens which leads to a decrease in worker's productivity and creativity.

Providing workers with a product that encourages them to work and takes care of their health is not an easy job hence the project in hands aims to eliminate the difficulties faced at work and improve work conditions.

Smart Desk is an innovative solution that registers a person's daily routine, gently notifies him/her of the best times to sit and stand. It is a combination of a desk with sensors and an application that consists of a schedule program where all orders are received by the Arduino controller, via Bluetooth, which orders the motor driver to activate the corresponding output.

\section{a) Statement of the Problem}

The $21^{\text {st }}$ century is the digital age where books are replaced by technological gadgets, and where employees, office workers, students, and managers spend a lot of hours sitting in the same position, focusing on small screens, writing reports, and achieving their own daily stuff without noticing that their health is negatively affected, hence suffering from health problems that limit their creativity and productivity.
Hence, according to a research conducted by MAYO CLINIC, it had been shown that sitting for long periods of time can result in an increase number of health concerns including obesity and metabolic syndrome, high blood sugar, excess body fat around the waist and abnormal cholesterol levels [1].

\section{b) Hypothesis or Key Questions}

There are a lot of needs that the office worker asks for them in order to have a comfortable, reliable and an automated technological environment, that are the best ways for a productive work. Some of the problems are listed below:

1) An adjustable desk that allows the user to feel better while he's working. Also the size of the office, and the important question: why the user doesn't have its transportable desk?

2) A working schedule that is organized from the morning to the evening, and some health problems such as neglecting the three initial dishes during the day, sitting for a while without moving, enhancing the mood with respect to the environment, and forgetting issues such as calling partners or identifying a user.

\section{c) Proposed Solution}

Desks are more than just furniture. They are where problems are solved, ideas created, and businesses are built; that's why Smart Desk was created. No desk is more advanced, or more effective than Smart Desk and here it comes the proof. Smart desk is not just a desk, this desk will rise to your height by reminding you to stand up after being sitting for too long to provide you with the perfect position while working. Not to forget, Smart Desk uses a reminder system that reminds you to eat on lunch time, drink water to keep 
your body hydrated, call a partner in case you forget, call a taxi when you want to leave, adjust light projection on your desk and the room temperature according to the environmental conditions. What makes this project unique is that it contains two main features: image processing and voice recognition. To allow more flexibility, Smart Desk is designed to be portable and be taken anywhere to serve user's needs [2].

\section{Materials and Methods}

\section{a) Alternative Design Approaches}

\section{Hardware}

There are many independent companies that are specialized in manufacturing office desks and automation systems, these companies design and create their own kits starting from data acquisition to end up with many designs for the desk, some of them use Auto Cad and others Auto Desk Inventor. The Smart Desk will be designed on the Auto Desk Inventor professional program that allows you to create the main parts of the desk body, assemble all the components, and show measures and sizes of your design. This program not only offers you a creative environment, but also allows you to draw the sheet of materials that includes all the measures, and to record your work with all the features as a final state. The figures below show the design [3].

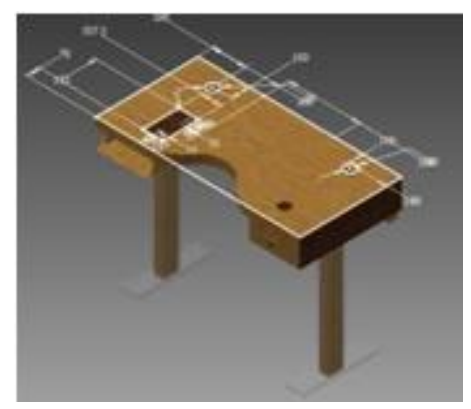

Figure 1: Desk Design on inventor

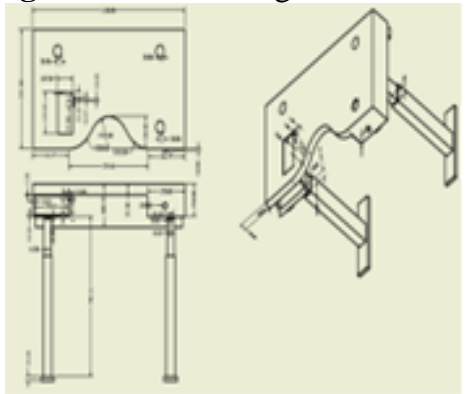

Figure 2: Drawing sheet of the desk

\section{Peripherals}

The minor importance of the system is to organize the day of an office worker from the time he enters his office, until he leaves. Using principle component analysis technique; a statistical method to decrease the variables where the eigen vectors in the training set obtained from covariance matrix are called eigen faces. In addition, this desk is also designed for the student to get rid of the school bag, books, and to organize his schedule, exams and tutorials. By projecting a testing set onto the subspace of the eigen faces and then estimating the Euclidean smallest distance the recognition and classification procedure can be accomplished.Concerning security and privacy, image processing is used and it is based on the user's face, it also identifies the user's guests.

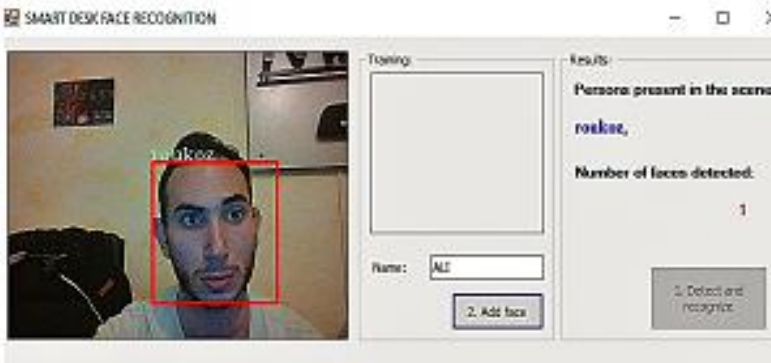

Figure 3: Image Processing Diagram.

Programming language

The main two programming languages used are $\mathrm{C \#}$ and XAML where the programs are coded using Visual Studio program. The Arduino IDE software is designed to deal with C programming language in order to write the GSM, voice recognition, Bluetooth, and 8 channel relay programs. Visual basic is used to design the windows application. Windows OPEN $\mathrm{CV}$ is used for the image processing feature[4].

\section{b) Selected Design Approaches}

\section{Technical Capabilities}

The framework proposed requires some specialized capacities summed by the learning and experience, including Arduino information and image processing background. Keeping in mind the end goal to have some information in registers frameworks and processors, likewise programming improvement including web and windows advancement. However, the designer should have a general outline on inventor program and how it works including assembly and the drawing sheets.

\section{Cost and Experience}

The Arduino and the windows improvement condition, concede the engineers an extraordinary favorable position over different outlines. These outlines have a relative highly cost since the undertaking joins between the computerization and the plan.

\section{Development Time}

Since the assigned project done by the help of open source licensed programs like Arduino IDE 1.8, Visual Studio, Visual Basic and OPEN CV, the development time would be reduced

\section{c) Design Specifications}

The desk is tightly designed according to the figure below. The main specifications of the system are wrapped around the Internet of Things, and it is considered an important tool or feature that can be added to the connected world in order to provide the user with a comfortable environment of communication. The desk can be adjusted with respect to your position and posture, this task is accomplished by the Arduino that gives the order for the eight channel relay module to be normally close so that the pistons are activated and can extend the desk for twenty five centimeters, once you accept the notification which insists on the sitting time. 
The application designed on Visual Basic, can organize your day and the schedule of meetings. Many voice commands can be given to the voice recognition module and many responds will be issued. The libraries of the image processing system will be installed on the tablet with windows OPEN CV to assure the compatibility with the camera in order to recognize the users and their guests. Besides that, the Arduino can monitor and control the desk; it can be connected to the camera and the tablet by using a Bluetooth shield to manipulate data received from the sensors, the camera and the user. Not to forget to mention that the desk can receive calls and SMS by the GSM shield connected to the Arduino which interfaces with the tablet[5].

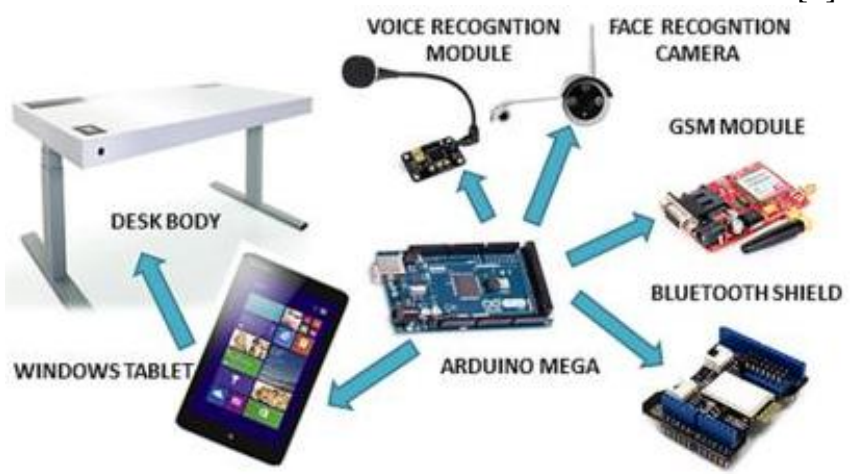

Figure 4: System Design

\subsection{Materials}

\section{1) Arduino Mega}

The Arduino Mega is a microcontroller board based on the ATmega1280. It has 54 digital input/output pins. It contains everything needed to support the microcontroller; simply connect it to a computer with a USB cable or power it with an AC-to-DC adapter or battery to get started. In this project, the orders are received by the Arduino controller via Bluetooth which gives an order for the motor driver that activates the corresponding output [6].

\section{2) Pistons}

A piston is an electrical motor that slides up and down inside tubes and cause various parts of the engine to move. It simulates the actuator in order to move the desk up and down[7].

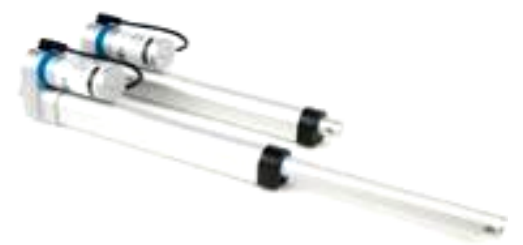

Figure 5: Arduino Mega

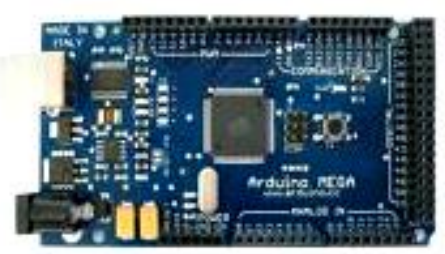

Figure 6: Electric Pistons

\section{3) GSM Module}

With the Arduino GSM Shield the library empowers an Arduino board to do the greater part of the operations you can do with a GSM telephone: put and get voice calls, send and get SMS, and associate with the web over a GPRS arrange. The GSM shield has a modem that exchanges information from a serial port to the GSM network. The modem executes operations by means of a progression of AT orders. The library abstracts low level interchanges between the modem and SIM card [8].

\section{4) Voice Recognition Module}

The voice recognition module works at an information voltage scope of 4.5 - 5 volts and will draw a current under $40 \mathrm{~mA}$. This module can work with $99 \%$ acknowledgment exactness in the event that it is utilized under perfect conditions. The decision of receiver and the clamor in nature assumes an essential part in influencing the execution of the module [9].

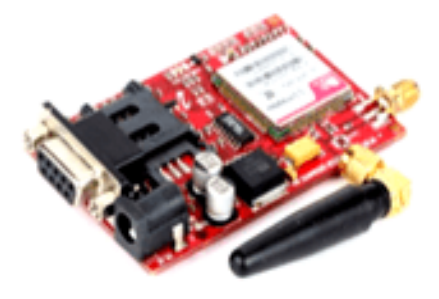

Figure 7: GSM Module

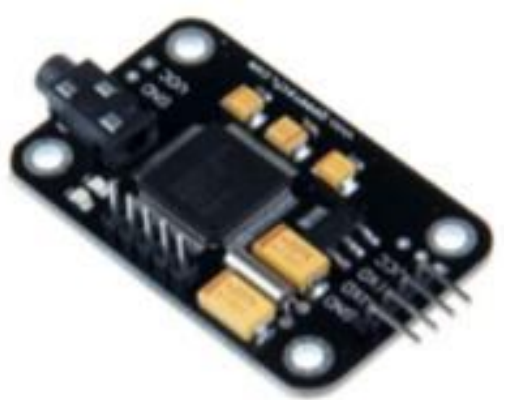

Figure 8: Voice Recognition module

\subsection{Methods}

Many steps should be followed in order to get a senior project that covers all the tasks listed in the previous paragraphs:

- Drawing all the parts with the appropriate measurements, then assembling them to have the desk body, using inventor professional program.

- Printing the drawing sheets designed on the inventor from the simplest draw to the most complicated.

- Writing down all the tasks and the features which will be accomplished during our progress.

- Checking for the availability of all the components such as the tablet, sensors, shields, camera and others.

- Designing a flowchart for the application and listing all the options which are involved in the design.

- Identifying the Arduino software and being familiar with all the required programs for the interface by using Arduino

IDE 1.8

- Working on the image processing program and its interface with the Arduino and the windows application.

- Starting by the implementation of the programs for the application using visual studio. 
- Testing the interface between the Arduino and the servo motors that allows the adjustment of the desk body.

- Linking the Arduino, tablet, camera, shields, sensors, and motors all together.

- Recording many voice orders using the voice recognition module. Such as, light on/off, music on/off, call home, open book stair and others.

- Entering pictures for image processing system so the user and the visitors are easily identified.

- Implementing the desk body.

- Connecting all the components together.

- Testing the system in order to avoid problems concerning connections and interfaces.

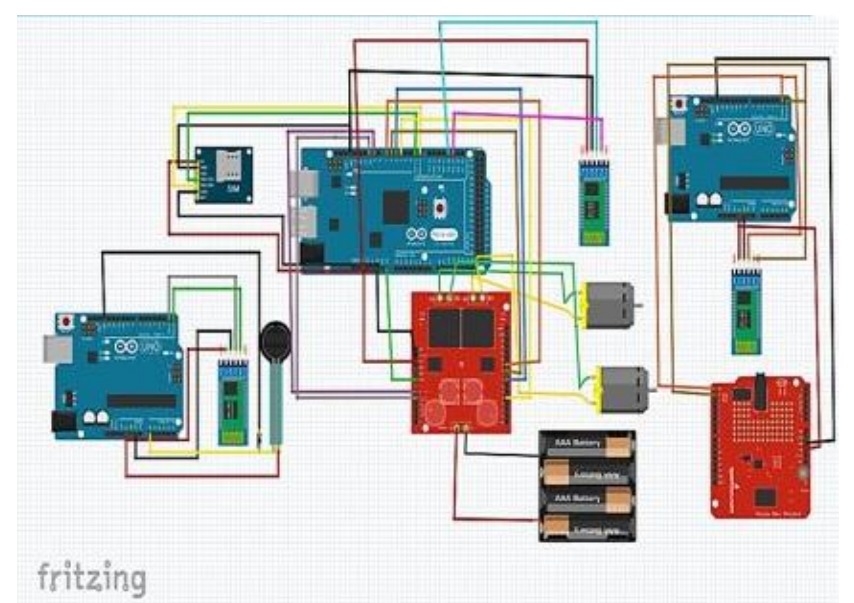

Figure 9: Circuit Schematic

\subsection{Cost Analysis}

Table 1: Cost Description

\begin{tabular}{|c|c|c|c|c|}
\hline Item & Description & Quantity & \begin{tabular}{|l} 
Price \\
(USD)
\end{tabular} & Total \\
\hline Arduino & Mega & 1 & $\$ 14.00$ & $\$ 14.00$ \\
\hline 5Mp Camera Module & Arduino & 1 & $\$ 60.00$ & $\$ 60.00$ \\
\hline GSM Module & Arduino & 1 & $\$ 30.00$ & $\$ 30.00$ \\
\hline $\begin{array}{c}\text { Voice Recognition } \\
\text { Module }\end{array}$ & Arduino & 1 & $\$ 48.00$ & $\$ 48.00$ \\
\hline Servo Motor & $9 \mathrm{G}$ & 1 & $\$ 4.00$ & $\$ 4.00$ \\
\hline $\begin{array}{l}\text { 8-channel Relay } \\
\text { Module }\end{array}$ & Arduino & 1 & $\$ 6.00$ & $\$ 6.00$ \\
\hline 9V Adapter & $\begin{array}{l}\text { Arduino Power } \\
\text { Supply }\end{array}$ & 1 & $\$ 6.00$ & $\$ 6.00$ \\
\hline 5V Adapter & $\begin{array}{l}\text { Relay Power } \\
\text { Supply }\end{array}$ & 1 & $\$ 5.00$ & $\$ 5.00$ \\
\hline Arduino Jumpers & M/F - 40/strip & 2 & $\$ 2.00$ & $\$ 4.00$ \\
\hline Arduino Jumpers & $\mathrm{M} / \mathrm{M}-40 /$ strip & 1 & $\$ 1.67$ & $\$ 1.67$ \\
\hline $\begin{array}{c}\text { Fluorescent LED } \\
\text { Tube }\end{array}$ & $12 \mathrm{~V}$ & 1 & $\$ 7.00$ & $\$ 7.00$ \\
\hline Consumables & $\begin{array}{c}\text { Wires, Heat } \\
\text { Sinks, } \\
\text { Electrical } \\
\text { Tape... } \\
\end{array}$ & 1 & $\$ 10.00$ & $\$ 10.00$ \\
\hline Desk Body & $\begin{array}{c}\text { Wood/ } \\
\text { Aluminum }\end{array}$ & 1 & $\$ 200.00$ & $\$ 200.00$ \\
\hline Lenovo MIIX 310 & Tablet & 1 & $\$ 230.00$ & $\$ 230.00$ \\
\hline Raspberry Pi & Raspberry Pi 3 & 1 & $\$ 60.00$ & $\$ 60.00$ \\
\hline Chair & Desk chair & 1 & $\$ 50.00$ & $\$ 50.00$ \\
\hline Pistons & Electric & 4 & $\$ 140.00$ & $\$ 560.00$ \\
\hline Desk Cost & & & & $\$ 1395.67$ \\
\hline Labor Cost $^{1}$ & & & & \begin{tabular}{|l|}
$\$ 1620.00$ \\
$\$ 3015.67$ \\
\end{tabular} \\
\hline
\end{tabular}

\section{Results and Discussion}

\section{A. Testing and Validation}

After we finish the software and hardware part, we start to implement all the components, modules, processors, and circuits on the desk. These parts are connected to the tablet via a serial and wireless communication. Then we test each feature as follows:

1) The motion of the desk with respect to the user; where it moves up to attend a maximum height of $110 \mathrm{~cm}$ when the user had been sitting for a certain period of time allowing the Arduino, which is connected to the chair, to give the order to the speakers to say the following: "you've been sitting for one hour and a half, would you like to stand up". This is done via a Bluetooth communication between the tablet and the Arduino.

2) Voice recognition is active and can detect many orders whether as a respond to the questions of the desk such as: "it's time for lunch what do you want to eat", "your first meeting is at 10 'o clock with Mr. James", or as a regular order to the desk to do some actions as: "call MacDonald's", "good morning desk", “desk close", "move up", "move down".

3) The windows application is designed with a dual mode where the worker mode contains working features such as: call a taxi, play/stop and pause music, order food, light slider, notes, and up/ down movements. Besides that, the student mode contains learning features such as: class books, tutorials, exam's schedule, and library. This application is used to set new events and notifications that the desk can state them verbally to remind the user.

4) The image processing feature, where the camera placed at the middle of the desk, is able to capture user's and guest's pictures in real time with information about their names and backgrounds. Once the desk is used for a second time by them, the camera is able to square the face and tell the name of the recognized person.

\section{B. Results}

Table 2: Desk Features

\begin{tabular}{|c|}
\hline Worker Mode \\
\hline Moving up/ down \\
\hline $\begin{array}{c}\text { Voice reminder system } \\
\text { (Eating, drinking, meeting, leaving, calling...) }\end{array}$ \\
\hline $\begin{array}{c}\text { Verbal orders } \\
\text { (Food, music, light control, move up, move down...) }\end{array}$ \\
\hline Guest's and user's identification \\
\hline $\begin{array}{c}\text { Mobility } \\
\text { (indoor, outdoor) }\end{array}$ \\
\hline Student Mode \\
\hline Moving up/ down \\
\hline $\begin{array}{c}\text { School's schedule } \\
\text { (course materials) }\end{array}$ \\
\hline Exam's schedule \\
\hline Class books and tutorials \\
\hline
\end{tabular}


Table 3: Voice Commands and Respondes

\begin{tabular}{|c|c|}
\hline Voice command & Voice respond \\
\hline $\begin{array}{l}\text { Hello desk (when the } \\
\text { user sit) }\end{array}$ & $\begin{array}{c}\text { Please log in (tablet log in whether } \\
\text { student or office worker based on image } \\
\text { processing if possible so it identifies the } \\
\text { user.) }\end{array}$ \\
\hline today's schedule & $\begin{array}{c}\text { Your first meeting with Mr. someone at } \\
10 \text { am } \\
\text { Your second meeting with your partners } \\
\text { at } 12 \mathrm{pm}\end{array}$ \\
\hline Call Someone & Calling Someone.... \\
\hline Call taxi driver & Calling Taxi driver. \\
\hline $\begin{array}{l}\text { Stand up desk (after the } \\
\text { voice reminder that } \\
\text { tells you to stand up) } \\
\end{array}$ & $\begin{array}{l}\text { You have been sitting for } 1 \text { hour and a } \\
\text { half, would you like to stand up. }\end{array}$ \\
\hline $\begin{array}{l}\text { Sit down desk (after the } \\
\text { voice reminder that } \\
\text { tells you to sit down) }\end{array}$ & $\begin{array}{l}\text { You have been moving for } 1 \text { hour would } \\
\text { you like to sit down }\end{array}$ \\
\hline $\begin{array}{l}\text { Macdonald's (after the } \\
\text { voice reminder) }\end{array}$ & $\begin{array}{l}\text { It's lunch time } 1: 30 \text { o'clock what do } \\
\text { you prefer to eat }\end{array}$ \\
\hline No voice command & $\begin{array}{c}\text { Please drink water (@ } 11 \text { am; } 1 \text { pm; } 3 \\
\text { pm ) }\end{array}$ \\
\hline Music on & Music is turned on \\
\hline Next music & The next song \\
\hline No voice command & It's time to leave (@3 pm) \\
\hline
\end{tabular}

\begin{tabular}{|c|}
\hline Welcome Worker \\
\hline Face Recognition \\
\hline Order Food \\
\hline Call Taxi \\
\hline Play Music \\
\hline Stop Music \\
\hline Pause Music \\
\hline Move up \\
\hline Move Down \\
\hline Notes \\
\hline
\end{tabular}

Figure 10: User interface for workers

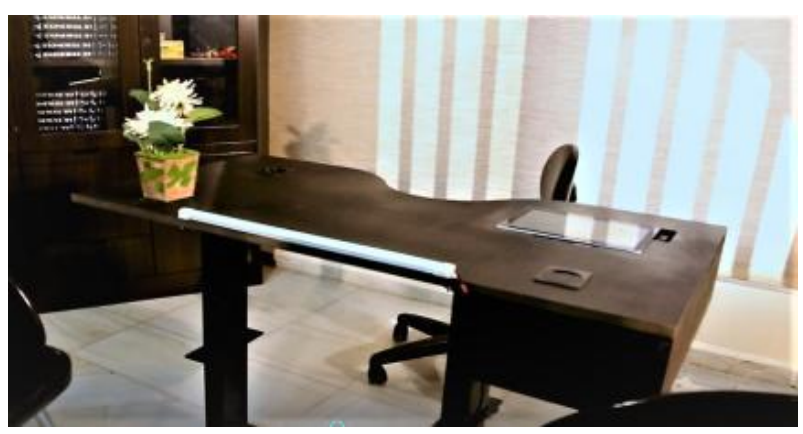

Figure 11: Sitting time estimation chair

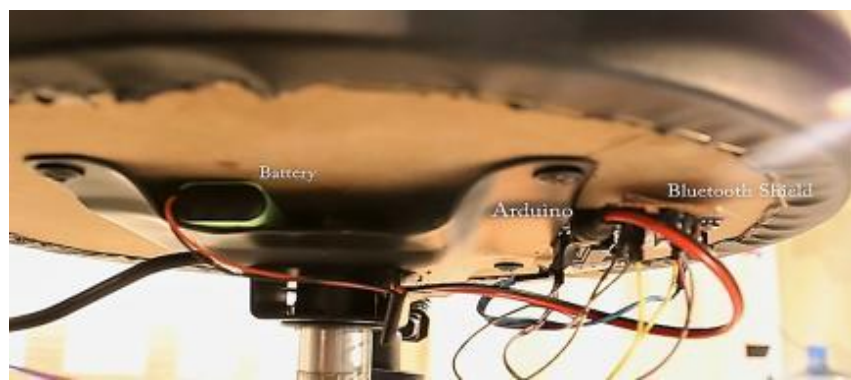

Figure 12: The automated desk

\section{Disscussion}

Representatives think the most about their chance, wellbeing and profitability. Imagine a scenario in which there is an item that can guarantee every one of these requests in an extremely straightforward outline. All organizations around the globe have a similar focus: to build specialist's profitability at the least conceivable cost and to expand efficiency premium work conditions must be fulfilled. Our item gives the client broad abilities by utilizing the application that enables the client to take control of all parameters. As specified in the previous chapters of the report, Smart work area has unique however related objectives that make work all the more fascinating for specialists. It weighs on the capacity to control and oversee time by presenting two basic highlights that are voice recognition and image processing.

Furthermore, it ensures that the client deals with its wellbeing by utilizing the update framework that tells the client to drink, eat, to stand up and to do some stretching exercises since sitting for delayed periods can make harm to our bodies.

\section{Conclusion and Future Work}

\subsection{Conclusion}

As mentioned in the previous chapters, Smart desk has different but related goals that make work more interesting for workers. It stresses on the ability to control and manage time by introducing two essential features that are voice recognition and image processing. In addition, it makes sure that the user takes care of its health by using the reminder system that notifies the user to drink, order food, to stand up and to do some stretching exercise since sitting for prolonged periods can cause damage to our bodies. The desk is unique because of its ability to respond to user's commands and interact with him. Also, it is able to replace traditional learning techniques that is adopted by the Lebanese schooling system, by a technological method that allows the student to get away of all the heavy books and follow the easiest way of learning by just a small screen that contains tutorials, class books, exams, and materials schedule. Thus say hello to a desk that replaces your assistant, school bag, books, and mobile phone.

\subsection{Future Work}

The mix between the equipment and the product makes the item an artful culmination. It is a stage forward in the realm of innovation that leads work to be more mindful, profitable, 
and imaginative. Additionally, it is much prescribed for some organizations and understudies in view of its unmistakable highlights in a single plan. The innovation is presently incorporated in a work area body used to control every one of the gadgets in a room with the end goal that the machines can improve the specialist's wellbeing much in view of its particular knowledge framework. This framework will be stretched out to a wide territory, with the goal that the client will be fulfilled and can have a decent efficiency in the work. Likewise, image processing framework can be utilized locally, as well as at the outside to give the client a fundamental foundation about the general population that meets with them.

The progression will be extended to attain other furniture and office supplies such as sofas, beds, kitchen, pillows, and closets to integrate user's life in the technological world.

\section{Acknowledgment}

I am extremely thankful to the Faculty of Engineering headed by Dr. NEDIM TUTKUN.

Big thanks go to my advisor Dr. EYLEM GÜLCE ÇOKERfor his valuable suggestions and encouragement.

Finally, I wish to extend my sincere thanks to my parents for their compassion and unlimited support.

\section{References}

[1] Edward R. Laskowski, M.D."What are the risks of sitting too much?". https://www.mayoclinic.org/healthy-lifestyle/adulthealth/expert-answers/sitting [April 2018].

[2] "The height-adjustable, standing Stir Kinetic Desk". Internet: https://www.stirworks.com [April 2018].

[3] Unknown. "Auto Desk Inventor". Internet: https://www.autodeskinventor.com/ [Feb2018].

[4] Unknown. "programming world". Internet: https://www.instructables.com/id/programmingworld[Ja n 2018].

[5] Unknown. "visual studio application". Internet: https://www.visualstudio.com/definition/reference/ardui nomega [Jan 2018].

[6] Unknown. "Arduino mega definition". Internet: https://www.arduino.cc/definition/reference/arduinomeg a [Jan 2018].

[7] Unknown. "electrical piston". Internet: https://www.instructables.com/id/definition/electricalpis ton/ [Jan 2018].

[8] Unknown. "GSM module". Internet: https://www.instructables.com/id/interfacing-SIM900AGSM-Modem-with-Arduino/ [Jan 2018].

[9] Unknown."Voice Recognition module". Internet: https://www.instructables.com/id/definition/voicerecogn itionmodule/ [Jan 2018]. 